\title{
ESTUDO DE CASO: SUSTENTABILIDADE DO BANCO REAL
}

SILVA, André Luiz de Carvalho ${ }^{1}$

NOLETO, Caroline Paschoim ${ }^{1}$

AMBROZINI, Marcelo Augusto ${ }^{2}$

Recebido em: 2009.11 .03

Aprovado em: 2010.03.30

ISSUE DOI: $10.3738 / 1982.2278-278$

RESUMO: Já há algum tempo, o Banco Real tem investido em sustentabilidade porque percebeu a importância dessa questão para a sociedade. Para realização do trabalho em questão foi feito um levantamento bibliográfico das práticas de sustentabilidade praticadas pelo Banco Real, através do Relatório de Sustentabilidade 2005 e 2006 com coleta de informações das ações realizadas e também os seus resultados. Os resultados da pesquisa foram apresentados em vários projetos realizados pelo Banco Real e que demonstram em cada ação o tipo de retorno obtido durante os anos de 2005 e 2006. Pode-se concluir que o retorno obtido é relevante, pois além dos benefícios financeiros gerados pelo Programa Amigo Real, também tem a questão da boa imagem da Empresa perante o mercado, devido a sua postura. Outro grande benefício conquistado por meio da adoção da sustentabilidade foi à implantação de um sistema de gestão ambiental na sede do próprio Banco, em São Paulo, levando o Banco Real a ser contemplado com a ISO 14001.

Palavra-chave: Sustentabilidade. Gestão. Meio Ambiente.

SUMMARY: For some time, the Banco Real has invested in suitability, because it realized the importance of this question to the society. To carry out this work, a bibliographic research was made by the Banco Real about the practices of suitability, through the Report of Suitability in 2005 and 2006, with collection of information of the actions carried out and also its results. The results of the research will be presented in several projects carried out by the Banco Real, which show in each action the type of the return obtained during 2005 and 2006 . We can conclude that the return obtained is relevant, because beyond the financial benefits conceived by the Program "Amigo Real", it also has the question of the good image of the Company in the face of the market, due to its posture. Another big benefit conquered by the adoption of the suitability was the introduction of a system of environmental administration in the home office of the own Bank, in São Paulo, so the Banco Real was contemplated with the ISO 14001.

Keywords: Suitability, Administration, Environment.

\section{INTRODUÇÃO}

Sustentabilidade é um conceito que vai muito além da longevidade de uma empresa. Prevê a gestão focada em três instâncias mutuamente fortalecedoras: a prosperidade da empresa, a qualidade ambiental dos sistemas que a envolve e a equidade social das comunidades que ela atua. Por atingirem um campo tão abrangente, os conceitos de sustentabilidade e gestão responsável têm extrapolado os limites da filantropia e assumido importância dentro da filosofia, dos valores e estratégias das empresas em todas as suas funções e áreas de atuação (FUNDAÇÃO DOM CABRAL, 2007).

\footnotetext{
${ }^{1}$ Pós-Graduandos em Gestão Empresarial da FE/FFCL

${ }^{2}$ Mestre em Controladoria e Contabilidade pela Faculdade de Economia, Administração e Contabilidade de Ribeirão Preto da Universidade de São Paulo - FEA-RP/USP e bacharel em Ciências Contábeis pela mesma instituição.
} 
A sustentabilidade tem sido um parâmetro cada dia mais utilizado por investidores na hora de escolher empresas, principalmente em segmentos conservadores que buscam segurança e constância no retorno. Socialmente responsável, ético, verde ou sustentável, são algumas denominações atribuídas ao processo de investimento que considera as consequências socioambientais, tanto positivas quanto negativas, em um contexto de rigorosa análise (LOPES, 2008).

Atualmente muitas empresas estão voltadas, dentro de seus negócios, para uma gestão sustentável, visando na maioria das vezes a certificação e a aceitação de seus produtos no mercado, que a cada dia se torna mais exigente e competitivo.

A pesquisa em questão traz a discussão sobre a sustentabilidade praticada pela instituição financeira Banco Real, que tem sido de grande relevância para o momento atual em que as pessoas muitas vezes ainda têm dúvidas sobre o assunto. E também como forma de divulgar o tema e mostrar se há benefícios gerados para quem pratica a sustentabilidade.

Existem diversas abordagens do tema sustentabilidade, o mais comum baseia-se nas vertentes econômica, social e ambiental, porém o presente trabalho tem como foco somente as análises ambiental e social da Gestão de desenvolvimento sustentável do Banco Real e identificar se há benefícios e retorno para o Banco devido às práticas de sustentabilidade realizadas.

A pesquisa tem como problema: Como são realizadas as práticas de sustentabilidade do Banco Real e o que lhe é oferecido de retorno?

O objetivo da pesquisa foi fazer um levantamento de como são realizadas as práticas de sustentabilidade do Banco Real e, posteriormente, verificar o que lhe é oferecido como retorno.

Para realização do trabalho em questão foi feita uma revisão bibliográfica através do Relatório de Sustentabilidade 2005 e 2006 das práticas de sustentabilidade realizadas pelo Banco Real, com coleta de dados de suas ações e também de seus resultados.

Além da pesquisa de literatura sobre o tema proposto no estudo, que teve como propósito levantar discussões sobre o assunto e despertar nas pessoas por meio deste exemplo o interesse por práticas que levem possíveis atividades a se tornarem sustentáveis.

\section{CONCEITO DE SUSTENTABILIDADE}

Segundo Gladwin (1995) apud Coral et al (2004), o desenvolvimento sustentável engloba três princípios básicos - equidade social, crescimento econômico e equilíbrio ambiental. O conceito amplo de sustentabilidade empresarial deve considerar estas três 
variáveis, e, portanto, uma vez que o crescimento econômico está presente na competitividade, pode-se concluir que a sustentabilidade de uma empresa dependerá de sua competitividade, da sua relação com o meio ambiente natural e de sua responsabilidade social. Sendo assim, em termos de conceito, a sustentabilidade engloba a competitividade, conforme demonstrado no quadro 1.

A disciplina da sustentabilidade está sendo desenvolvida e ainda não existe consenso em relação ao seu conceito, principalmente quanto a sua aplicabilidade no escopo empresarial. Assim, várias definições de sustentabilidade são utilizadas em situações distintas. Alguns autores defendem a idéia de que uma empresa será sustentável se não agredir o meio ambiente, detalhando o conceito de sustentabilidade ecológica ou organizações ecologicamente sustentáveis (ATKINSON, 2000; HOFFMAN, 2000; GLADWIN, 1995; HAWKEN, 1993). Neste caso, a sustentabilidade está embasada pela teoria ecológica, sendo alcançada quando a extração de recursos naturais ocorre dentro da capacidade de reposição natural da base de recursos e, quando os resíduos sólidos transferidos para os componentes físicos do sistema ecológico não ultrapassam a capacidade de assimilação dos ecossistemas (DALY; COBB, 1994; SHRIVASTAVA, 1995).

\begin{tabular}{|c|c|}
\hline Competitividade & Sustentabilidade \\
\hline Baseada em fatores econômicos e operacionais & $\begin{array}{l}\text { Baseada em fatores econômicos, sociais e } \\
\text { ecológicos }\end{array}$ \\
\hline $\begin{array}{l}\text { Visão de mundo restrita - empresa contra as } \\
\text { forças competitivas }\end{array}$ & $\begin{array}{l}\text { Visão de mundo mais ampla - parcerias para obter } \\
\text { vantagens competitivas }\end{array}$ \\
\hline $\begin{array}{l}\text { Legislação ambiental = aumento de custos de } \\
\text { produção }\end{array}$ & Legislação ambiental = promoção da inovação \\
\hline Uso de tecnologias de produção tradicionais & Uso de tecnologias limpas de produção \\
\hline $\begin{array}{l}\text { Questões do meio ambiente natural geralmente } \\
\text { são vistas como ameaças }\end{array}$ & $\begin{array}{l}\text { Questões do meio ambiente natural geralmente } \\
\text { são vistas como novas oportunidades }\end{array}$ \\
\hline $\begin{array}{l}\text { Foco na redução de custos e eficiência } \\
\text { operacional }\end{array}$ & Foco na inovação \\
\hline Individualista & Cooperação \\
\hline
\end{tabular}

QUADRO 1: Resumo comparativo entre sustentabilidade e competitividade FONTE: Gladwin (1995) apud Coral (2004) et al.

Embora exista uma definição amplamente aceita para o conceito de desenvolvimento sustentável, que é "o desenvolvimento que satisfaz as necessidades presentes, sem comprometer a capacidade das gerações futuras de suprir suas próprias necessidades", existe um grande debate quanto à definição correta do termo sustentabilidade corporativa, por sua 
associação com termos já anteriormente conhecidos no meio empresarial como responsabilidade social, responsabilidade social corporativa ou cidadania corporativa. (LINS; WAJNBERG, 2007).

Entretanto, mesmo não possuindo um forte impacto socioambiental direto, o setor financeiro possui alto impacto indireto, que se dá principalmente por meio de suas atividades de financiamento para seus clientes e no seu relacionamento com seus fornecedores. $\mathrm{O}$ principal papel dos bancos no desenvolvimento sustentável, portanto, não é um papel de executor de mudanças, mas sim de indutor de mudanças nas partes com as quais se relaciona. Exercendo este papel, os bancos brasileiros, considerando seu considerável porte, capilaridade e potencial de geração de empregos, podem contribuir enormemente para a mudança de postura de grande parte da sociedade brasileira. (LINS; WAJNBERG, 2007).

A Figura 1 mostra que frequentemente associado ao termo sustentabilidade corporativa, e de fundamental importância para a compreensão do tema, é o conceito do triple bottom line - TBL, proposto por John Elkington em 1998 em seu livro "Canibais com Garfo e Faca”. O conceito do TBL refere-se basicamente à prosperidade econômica, qualidade ambiental e progresso social, e à construção de métricas que permitam mensurar a atuação de uma empresa não só na esfera econômica, mas também nas esferas social e ambiental. (LINS, WAJNBERG, 2007).

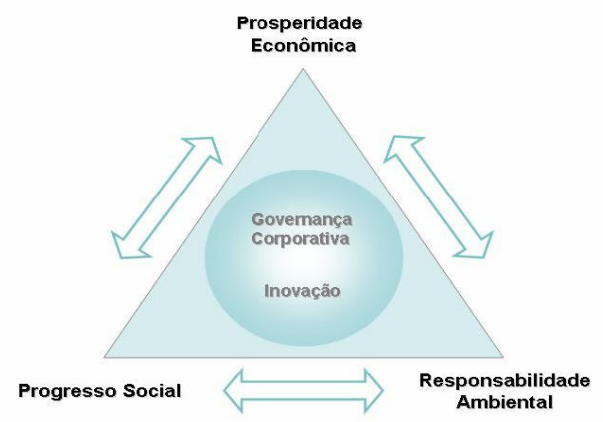

FIGURA 1 - Triple Bottom Line

FONTE: Lins e Wajnberg, 2007

Sustentabilidade corporativa não significa necessariamente maiores custos, processos mais burocráticos e menores retornos financeiros. Sustentabilidade repousa em uma visão de negócios onde desempenho socioambiental caminha lado a lado ao desempenho econômico uma mudança de paradigma que prioriza a perenidade e a perpetuidade da organização. Em 
algumas situações, a melhoria no desempenho socioambiental pode gerar ganhos financeiros de curto prazo para as organizações - vide, por exemplo, oportunidades oriundas da comercialização de créditos de carbono. Em outras, esta melhoria pode não gerar benefícios imediatos, porém traz à empresa ganhos de longo prazo, que contribuem justamente para o sucesso contínuo e perene da organização. Assim, uma situação onde melhorias socioambientais estão ligadas primariamente a perdas econômicas viola um dos tripés do TBL, e não é sustentável. (LINS; WAJNBERG, 2007).

Muitas das iniciativas de sustentabilidade dos bancos brasileiros não ganham correspondente divulgação e, por consequência, devido reconhecimento pelas partes interessadas. Além disso, a grande carência de indicadores nos documentos públicos das empresas inviabiliza qualquer avaliação mais completa de desempenho socioambiental. É preciso que o setor financeiro se abra ao diálogo e preste contas à sociedade sobre a totalidade de ações de suas instituições na agenda da sustentabilidade, inclusive estabelecendo metas de atuação. Esse maior nível de transparência mostrará seu real comprometimento com o tema e estimulará o engajamento da própria sociedade com a instituição, contribuindo, inclusive para um melhor entendimento acerca do papel dos bancos na sociedade. (LINS; WAJNBERG, 2007).

Dentro desse contexto, observa-se que muitas empresas vêm procurando utilizar o conceito de sustentabilidade, inclusive as instituições financeiras, como é o caso do Banco Real S.A., que segundo Maria Luiza Pinto, Diretora Executiva de Desenvolvimento Sustentável do Banco, a sustentabilidade precisa fazer parte do negócio como um todo e não ser apenas uma iniciativa paralela ao negócio. Por conta dessa visão, desde 2001 o Banco Real trabalha para aliar os aspectos socioambientais aos econômicos, rotineiros ao mercado financeiro. (MARTINS, 2008)

Já há algum tempo, o Banco Real tem investido em sustentabilidade porque percebeu a importância dessa questão para a sociedade. No entanto, não se tratava apenas de uma mudança de imagem, ou reposicionamento da marca. As práticas de sustentabilidade fazem parte da visão de negócios da instituição. (MARTINS, 2008)

Inúmeras práticas são realizadas pela instituição em parceria com organizações, tentando desta maneira levar a inclusão do desenvolvimento sustentável em suas estratégias de negócio e cultura de gestão. Todas estas práticas que vão das mais simples, como o uso de papel reciclado às mais complexas, como a liberação de crédito mediante garantias ambientais, podem ser encontradas no Espaço Real de Práticas Sustentáveis. (BANCO REAL, 2008) 


\section{REVISÃO DE LITERATURA}

Marques e Alledi (2004) analisaram a sustentabilidade nas empresas brasileiras, particularmente no sistema financeiro, através de estudo não exaustivo, abordando referenciais teóricos, oportunidades, ameaças e perspectivas futuras para o tema. A metodologia utilizada é a resenha bibliográfica analítica, coleta e confrontação de dados e informações, contatos e pesquisas, via internet, com instituições ligadas à responsabilidade social e à sustentabilidade, principais bancos e Federação Brasileira dos Bancos FEBRABAN. Destacam-se a análise do Balanço Social 2002 da FEBRABAN e a abordagem de empresas do setor consideradas benchmarking em algum de seus aspectos. $\mathrm{O}$ setor foi contextualizado à luz dos instrumentos que vêm sendo utilizados para incorporação do conceito de sustentabilidade ao negócio, frequentemente presente nas estratégias e na gestão do negócio, destacando-se: publicação do Balanço Social, associação com instituições como Instituto Ethos e CEBDS, volume significativo de recursos aplicados em ações sociais e culturais, e investimento em educação e formação profissional dos empregados. Carecem de maior atenção questões como diversidade, envolvimento dos fornecedores e parceiros na busca da sustentabilidade e ainda sua vertente ambiental, particularmente no tocante ao crédito como indutor do respeito ao meio ambiente.

Coral et al (2004) apresentaram um modelo de planejamento estratégico para a sustentabilidade empresarial. Para tanto, desenvolveu os conceitos de sustentabilidade empresarial, organizações sustentáveis, estratégias ambientais e sociais, além de realizar uma análise crítica dos modelos de planejamento estratégico existentes na literatura. As análises mostraram que os modelos de planejamento estratégico existentes estão fundamentados principalmente em fatores econômicos e na competitividade, não englobando de forma sistêmica os fatores ambientais e sociais. Além disto, a utilização de estratégias ambientais e sociais de forma pró-ativa podem levar as empresas a melhoria de sua competitividade. A partir das carências dos modelos existentes frente às novas necessidades de sustentabilidade empresarial, desenvolveu-se um novo modelo de Planejamento Estratégico que incorpora as variáveis meio ambiente natural e responsabilidade social na gestão estratégica das empresas.

Pereira et al (2006) analisou a construção do conceito de responsabilidade social corporativa no contexto bancário do ABN AMRO REAL, por meio de um estudo de caso, no qual abordou-se o contexto da instituição financeira pesquisada, sua estrutura e sua estratégia de responsabilidade social corporativa e ambiental, ou seja, os motivos que levam as instituições financeiras a adotarem seus princípios. Para tanto, foram selecionadas algumas 
ações que caracterizaram a gestão de responsabilidade social corporativa, para relacioná-los com ações sociais do segmento bancário. Elaborou-se uma revisão bibliográfica sobre o assunto, na qual pôde-se constatar a relevância do tema responsabilidade social corporativa, bem como sua complexidade no setor bancário. A partir dos conceitos encontrados na literatura formulou-se um referencial teórico que orientou um estudo de caso realizado em uma instituição financeira. Discorreu-se sobre os principais conceitos relacionados à responsabilidade social corporativa e sustentabilidade, bem como o processo de incorporação da responsabilidade social no contexto bancário. Este estudo de caso almeja entender os fatores que estão levando o segmento bancário a adotar a responsabilidade social corporativa, de que forma estão construindo e disseminando o conceito junto aos stakeholders. O resultado da pesquisa sugere que banco estudado, por meio de várias ações, construiu e disseminou o conceito de responsabilidade socioambiental em seu conglomerado e vem implementando ações corporativas voltadas para tal fim.

Costa (2007) buscou investigar a associação existente entre a adoção de praticas de sustentabilidade e preços das ações de companhias brasileiras listadas no Índice de Sustentabilidade Empresarial (ISE). Os problemas envolvendo a sustentabilidade do desenvolvimento socioeconômico tornaram-se uma questão globalizada. Em todas as partes do mundo, o interesse sobre a questão é notório. Diversos ramos de atividades governamentais, não governamentais, públicos e privados - estão cada vez mais inseridos, na busca de uma sociedade responsável com as gerações futuras. Demonstrou-se, que para se tornarem sustentáveis as companhias adotam duas praticas fundamentais: Governança Corporativa e Responsabilidade Socioambiental. Argumenta-se que, sob uma perspectiva estritamente financeira, a adoção de praticas de sustentabilidade empresarial pode estar relacionada ao aumento de gastos, porém estas também podem trazer benefícios, como redução de eventuais passivos ambientais. Para verificar a existência de relação positiva entre o maior nível de sustentabilidade empresarial e valoração dos preços das ações de companhias brasileiras, aplica-se testes econométricos a séries históricas dos preços de ações que compõem o ISE, utilizando-se como referência comparativa o Ibovespa e IBrX. Com base nos resultados obtidos, não foi possível rejeitar a hipótese de que não existe relação positiva entre o maior nível de sustentabilidade empresarial e valoração do preço das ações de companhias brasileiras.

Lins e Wajnberg (2007) buscaram analisar o entendimento e a incorporação do conceito da sustentabilidade corporativa nas principais instituições do setor bancário brasileiro. Para tanto, foram realizadas 67 entrevistas com altos executivos dos 10 maiores 
bancos, juntamente com a aplicação de 126 questionários direcionados aos entrevistados e ao nível gerencial médio. Embora não possua um forte impacto socioambiental direto, o setor financeiro possui alto impacto indireto, que se dá principalmente por meio de suas atividades de financiamento para seus clientes e no seu relacionamento com seus fornecedores. Esta pesquisa revela que o setor já está inserindo os aspectos sociais e ambientais em suas tomadas de decisões. No entanto, existe enorme discrepância entre as práticas e o reporte das mesmas nas instituições analisadas: enquanto algumas instituições mostram clara liderança na incorporação da sustentabilidade nos negócios e na sua correspondente divulgação, fica também evidente que outras instituições estão apenas começando a considerar aspectos socioambientais no dia-a-dia dos negócios. A realização de entrevistas com os altos executivos do setor bancário brasileiro permite concluir que os responsáveis pelo pensamento estratégico já reconhecem a importância da questão e já estão promovendo mudanças em suas estratégias, modificando suas visões de longo prazo, estruturas organizacionais e práticas de negócios, com o objetivo de melhor incorporar o tema da sustentabilidade corporativa. Em último lugar, coloca-se o desafio de dar mais transparência ao desempenho socioambiental das instituições bancárias. Muitas das iniciativas de sustentabilidade dos bancos brasileiros não ganham correspondente divulgação e, por consequência, devido reconhecimento pelas partes interessadas. Além disso, a grande carência de indicadores nos documentos públicos das empresas inviabiliza qualquer avaliação mais completa de desempenho socioambiental. É preciso que o setor financeiro se abra ao diálogo e preste contas à sociedade sobre a totalidade de ações de suas instituições na agenda da sustentabilidade, inclusive estabelecendo metas de atuação.

\section{RESULTADOS E DISCUSSÃO}

Os resultados da pesquisa estão apresentados em vários projetos realizados pelo Banco Real e que demonstram em cada ação o tipo de retorno obtido durante os anos de 2005 e 2006. Os projetos a seguir foram extraídos do Relatório de Sustentabilidade de 2005 e 2006 elaborado pelo Banco Real, no qual utilizaram uma estrutura de indicadores baseada em iniciativas internacionais e nacionais dedicadas a promover o relato sobre impactos econômicos, sociais e ambientais de suas atividades. São a Global Reporting Initiative (GRI), o Guia de Elaboração do Balanço Social, do Instituto Ethos, Empresas e Responsabilidade Social, além de modelos do Ibase, e da Federação Brasileira dos Bancos (FEBRABAN) entre outros. 


\section{PROGRAMA AMIGO REAL}

Com início em 2002 este programa teve como objetivo facilitar o direcionamento da parte do Imposto de Renda aos fundos dos direitos da criança e do adolescente, administrados pelos conselhos dos Direitos da criança e do adolescente de novo, para apoiar projetos sociais com foco em educação. Fortalecer o papel dos conselhos na sua atuação em prol da criança e do adolescente. Tendo como público beneficiado crianças e adolescentes de municípios que apresentaram IDI (Índice de Desenvolvimento Infantil) e IES (índice de exclusão social) em situações críticas. Conselhos municipais dos Direitos da Criança e do Adolescente. Contou com a parceria dos Conselhos Municipais dos Direitos da Criança e do Adolescente e do Apoio Institucional do UNICEF.

Os investimentos realizados pelo Banco Real no ano de 2005 e 2006 totalizaram R\$ 1.532.486,51 dentro do programa e mais $\mathrm{R} \$ 3.343 .508,80$ de divulgação na mídia, gerando um benefício fiscal de $\mathrm{R} \$ 2.747 .800,00$. Já os resultados deste mesmo período mostraram que cerca de 21.600 crianças e adolescentes foram beneficiadas em 77 projetos, com a colaboração 24.816 funcionários da organização arrecadando $R$ \$ 3.875.201,06 e também contaram com o apoio de 11.686 clientes, fornecedores e parceiros que juntos conseguiram para o projeto a quantia de $\mathrm{R} \$ 2.202 .081,68$. Além disto, as empresas do Grupo ABN AMRO colaboraram com $\mathrm{R} \$ 2.837 .000,00$.

\section{PROJETO ENERGIA PARA TRANSFORMAR}

Nos últimos dois anos, o Banco Real assessorou e financiou projetos de energia pelas cinco regiões do país, que juntos foram capazes de abastecer países inteiros, como o Uruguai. A partir disto podem-se citar seis subprojetos.

- Projeto Brasil PCH (ES, MG, GO, RJ) - (Petrobrás Distribuidora/Eletroriver/Acesa/BSB Energética) - Construção de 13 PCHs, com potência instalada total de 291 MW. É o maior projeto do Proinfra e a primeira operação de Portfolio Financing realizada com o BNDES. Investimento: $\mathrm{R} \$ 1,14$ bilhão.

- Projeto Ventos do Sul (RS) (Ventos do Sul) - Construção e operação de três parques eólicos em Ozório (RS), com capacidade instalada total de 150 MW. Envolve cinco bancos diferentes, além do ABN AMRO REAL. É considerado o maior parque eólico do Brasil e o segundo nas Américas em potência instalada. Investimento: $\mathrm{R} \$ 662$ milhões.

- Projeto CRIN (PR) (Bosch) - Implantação de linha de produção de injetores a diesel, denominados Common Rail Injektor (CRIN), para veículos pesados, na unidade de Curitiba da Bosch. A nova linha de sistemas de injeção tem capacidade instalada de 1,1 milhão de 
peças/ano e mais de $60 \%$ da produção será exportada. Investimento: R \$ 240 milhões.

- Projeto CERP (RS) (Hidrotérmica SA) - Construção e operação de duas PCHs, localizadas no Rio da Prata (RS), com potência instalada total de 54 MW. É a primeira operação aprovada pelo Fundo Infrabrasil. Investimento: R \$ 227,2 milhões.

- Projeto Rio do Fogo (RN) (Iberdrola) - Construção e operação de parque eólico de 49,3 MW de potência instalada, localizado no Rio do Fogo (RN). É considerado o primeiro parque eólico em larga escala a entrar em operação no Brasil. Investimento: R 210 milhões.

- Projeto ESPRA (BA) - Construção de três PCHs no sul da Bahia, com 41,8 MW de potência instalada. Foi a primeira operação de financiamento do Banco do Nordeste para PCHs. Investimento: R\$ 192 milhões.

- Projeto Guascor (AC, PA, RO) (Guascor do Brasil LTDA) - Refinanciamento do projeto que compreende termoelétricas que atuam no estado do Acre, Pará e Rondônia, produzindo energia por meio de geradores movidos a óleo diesel. Beneficiam 1,8 milhão de pessoas, em 71 cidades, com um total de potência instalada de 172 MW. Investimento: R \$ 82 milhões.

- Projeto GMR (SC) (GMR-Empreendimentos e Participações) - Complexo de duas PCHs (37 MW). Investimento: R 88,2 milhões.

\section{MUDANÇA NA VIDA (E NO BOLSO) DE TODOS}

O pioneirismo em promover operações em sintonia com as questões socioambientais e de governança corporativa despertou o interesse da Internacional Finance Corporantion (IFC), braço do Banco Mundial para o setor privado, que já aportou US\$ 125 milhões para a carteira de negócios sustentáveis do ABN AMRO REAL. Fomos o primeiro banco a conquistar a autonomia para realizar a análise de Projetos Socioambientais.

Assim, foi possível investir em um projeto inovador da TSL Engenharia Ambiental: o uso de tecnologia de plasma térmico para a reciclagem de embalagens longa-vida. $O$ desenvolvimento da tecnologia teve a participação de mais três empresas: Tetrapak, Alcoa e Klabin, envolvidas diretamente na produção das embalagens. Além das vantagens econômicas para as empresas, há claros benefícios para o meio ambiente, pois se utilizam menos insumos, e menos resíduos são descartados. O Banco viabilizou o financiamento para o reator que será enviado para uma fábrica na Espanha um projeto de US\$ 5,6 milhões.

No edifício-sede, na Avenida Paulista, em São Paulo, foi implementado um sistema de gestão ambiental, que resultou no recebimento da ISO 14001, em novembro de 2006. A certificação atesta os procedimentos de controle dos efeitos provocados no meio ambiente e os processos de melhoria contínua para aperfeiçoar o uso de recursos naturais. O prédio abriga 
4.500 pessoas, com um consumo mensal médio de 26 toneladas de lixo, $6.100 \mathrm{~m}^{3}$ de água e 1.635.999 kWh de energia. Com o sistema de gestão ambiental, passou-se a estabelecer metas para redução do consumo de água, energia e produção de lixo. Pilhas e baterias são recicladas, e seus óxidos, reaproveitados como pigmentos para a cerâmica. Lâmpadas usadas são descontaminadas e também recicladas. Óleos de cozinha e de geradores viram graxa. $\mathrm{O}$ lixo contaminado (solventes, tintas e materiais contaminados) é incinerado.

\section{CONCURSO TALENTOS DA MATURIDADE - VALORIZAÇÃO DA DIVERSIDADE}

Criado em 1999, em homenagem ao Ano Internacional do Idoso, o concurso incentiva a produção e a memória cultural de pessoas com 60 anos ou mais, promovendo a sua criatividade, ampliando seu potencial artístico e sua participação social. Estimula também a reflexão da sociedade sobre o envelhecimento, uma questão relevante em um país que, segundo projeções da ONU, terá 32 milhões de habitantes com mais de 60 anos em 2025.

A partir de 1999 este projeto teve por objetivo valorizar e incluir o idoso na sociedade, além de promover uma reflexão acadêmica sobre o tema envelhecimento. Conta com a parceria do SESC, SBGG, Ministério da Saúde e da Ação Social e CNBB, entre outros. Nos anos de 2005 e 2006 foram investidos $\mathrm{R} \$$ 8.483.424,00 e $\mathrm{R} \$ 10.927 .098,10$ de divulgação na mídia. Obtiveram-se como resultado neste biênio 57.268 trabalhos inscritos com um total de 38.201 participantes, sendo estes idosos.

\section{CONCLUSÃO}

A pesquisa teve o propósito de mostrar o retorno e os benefícios obtidos por meio das práticas realizadas através da adoção e incorporação do conceito de sustentabilidade do Banco Real, diferentemente de outras pesquisas analisadas sobre a gestão de sustentabilidade e responsabilidade social no setor bancário, que analisaram os motivos que levam as mesmas a adotarem esta gestão como estratégia ou princípio, demonstram que há algumas instituições que já a incorporaram em seus negócios promovendo mudanças em suas estratégias, práticas de negócios e nas suas tomadas de decisões, e por outro lado existem instituições que ainda estão começando a considerar aspectos socioambientais no seu dia-a-dia.

Analisando o levantamento de algumas práticas de sustentabilidade do Banco Real do Relatório de Atividades 2005 e 2006, pode-se concluir que o retorno obtido é relevante, pois além dos benefícios financeiros gerados pelo Programa Amigo Real, também tem a questão da boa imagem da empresa perante o mercado devido a sua postura. 
Outro grande benefício conquistado por meio da adoção da sustentabilidade foi a implantação de um sistema de gestão ambiental na sedo do próprio Banco, em São Paulo, levando o Banco Real ser contemplado com a ISO 14001, o que mostra que houve de fato o engajamento de todos os departamentos e colaboradores da empresa, o que é extremamente importante para o sucesso da sustentabilidade.

Observa-se então que questões como estas que foram adotadas pelo Banco Real e obtiveram êxito, fazem com que qualquer empresa independente do ramo, se torne mais bem quista por seus stakeholders.

Como proposta de práticas e pesquisas futuras de sustentabilidade, sugere-se o envolvimento da comunidade e da empresa nas questões ambientais no que se refere, por exemplo, ao aquecimento global ou desmatamento, como alternativa da redução de gases poluentes e ao mesmo tempo se colocando como um novo banco para uma nova sociedade.

\section{REFERÊNCIAS}

ATKINSON, G. Measuring corporate Sustainability. Journal of Environmental Planning and Management. v. 43, n.2, p. 235-252, 2000.

BANCO REAL. Manifesto: encurtar o caminho na direção de um mundo sustentável. Disponível em:

http://www.bancoreal.com.br/index_internas.htm?stUrl=/sobre\%20o\%20praticas/default.aspx Acesso em 06 jun. 2008.

COSTA, F. J. M. Sustentabilidade e desempenho financeiro: uma análise do mercado brasileiro de ações. 2007. 105f. Dissertação (Mestrado em administração). Universidade Federal da Bahia - Núcleo de Pós-Graduação em Administração, Salvador.

DALY, H. E.; COBB, J. C. For the Common Good. In: CORAL, E. A competitividade empresarial no contexto dos indicadores de sustentabilidade corporativa. Florianópolis, 2004. p. 3-4/7.

FDC - Fundação Dom Cabral. Gestão responsável para a sustentabilidade. São Paulo, 2007. p. 3.

GLADWIN, T. Shifting paradigms for sustainable development: implications for management theory and research. The Academy of Management Review. Mississipi, 1995. In, CORAL, E. et, al. A competitividade empresarial no contexto dos indicadores de sustentabilidade corporativa. Florianópolis, 2004. p. 3.

HOFFMAN, A. J. (2000). Environmental and social issues into corporate practice. In, CORAL, E. et, al. . A competitividade empresarial no contexto dos indicadores de sustentabilidade corporativa. Florianópolis, 2004. p. 3. 
HAWKEN, P. (1993) The ecology of commerce: a declaration of sustainability. In: CORAL, E. et, al. A competitividade empresarial no contexto dos indicadores de sustentabilidade corporativa. Florianópolis, 2004. p. 3.

LINS, C.; WAJNBERG, D. Sustentabilidade corporativa no setor financeiro brasileiro. Rio de Janeiro, 2007. p. 7-8.

LOPES, J. Sustentabilidade cai nas graças do investidor. Revista Idéia Socioambiental. Acervo Gazeta Mercantil. São Paulo.

http://www.ideiasustentavel.com.br/revista/gazeta_mercantil.php?codGazeta=52 Acesso em 17 jun. 2008.

MARQUES, V. L.; ALLEDI, C. Sustentabilidade empresarial no sistema financeiro brasileiro. CONGRESSO ACADÊMICO DE MEIO AMBIENTE E DESENVOLVIMENTO DO RIO DE JANEIRO, 1. Anais... Niterói, 2004.

MARTINS, A. Banco Real: um banco de boas ideias. Revista Imprensa. maio 2008. p.46. Disponível em: http://www.rivieragroup.com.br/Rev_IMPRENSA_Maio_2008.pdf. Acesso em 06 jun. 2008.

PEREIRA, M.; SARAIVA, M.; PEREIRA, R.. O papel das instituições financeiras frente a responsabilidade social corporativa: um estudo de caso. São Paulo: Saraiva, 2006. p. 5.

SHRIVASTAVA, P. (1995). Industrial Environment Crises and Social Responsibility. In, CORAL, E. et, al. A competitividade empresarial no contexto dos indicadores de sustentabilidade corporativa. Florianópolis, 2004. p. 3. 
